\title{
Socioeconomic Burden of Type 2 Diabetes with Complications on Families: A Hospital-Based Study in Puducherry
}

\author{
Manokaran Chinnusamy ${ }^{1}$ Sathiyanarayanan Janakiraman ${ }^{1}$ Roshna Elayidath ${ }^{1}$ Ram Arvind ${ }^{1}$ \\ Pravin Surendran ${ }^{2}$
}

1Department of General Medicine, Sri Manakula Vinayagar Medical College and Hospital, Pondicherry, India

2Department of Community Medicine, Sri Manakula Vinayagar

Medical College and Hospital, Pondicherry, India

\begin{abstract}
Address for correspondence Manokaran Chinnusamy, MBBS, MD, Department of General Medicine, Sri Manakula Vinayagar Medical College and Hospital, Kalitheerthalkuppam, Madagadipet, Pondicherry 605107, India (e-mail: manokaran.smvmch@gmail.com).
\end{abstract}

J Health Allied Sci ${ }^{N U}: 2021 ; 11: 28-34$

\begin{abstract}
Keywords

- diabetes mellitus

- complications

- healthcare expenditure

- cost of illness

Introduction India is on the verge of diabetes mellitus (DM) epidemic. Within the near future, DM will put a big burden on India's already vulnerable and resourced health care system. The objectives of the study were to (1) estimate DM treatment-related out-of-pocket expenditure (OOPE) among type 2 DM patients with complications from a tertiary care hospital and (2) estimate the economic burden on the household income of these patients due to DM treatment-related OOPE.

Methods A hospital-based cross-sectional study was conducted among known type 2 diabetic individuals with complications admitted in a tertiary care hospital. Using a structured pretested questionnaire required data, such as sociodemographic details, direct costs, and indirect costs in health care of DM, which were collected by a personal interview method.

Results Males constituted around $57 \%$ of the 100 patients who participated in the study. The average age of the population was $56 \pm 10.03$ years. The mean monthly income of family (in Indian Rupees [INR]) was 10,375.00 $\pm 9,201.55$. Total expenditure includes the cost of medication, investigation, consultation fee, transportation, and miscellaneous expenditure. The average monthly OOPE in the management of DM for government and private facilities was INR 74 and 1,540, respectively. Among the total cost, the highest share was accrued toward medicines followed by diagnostics, miscellaneous, and transportation. There were $22 \%$ of families incurring catastrophic expenditure at the highest threshold of $40 \%$. Socioeconomic status, history of at least one hospitalization in the past 6 months, and type of medications were factors found to be associated with costs.

Conclusion Heavy economic burden highlights the urgent need for the health care agencies and policy bodies to plan and prioritize local health policies and DM management schemes accordingly.
\end{abstract}

published online January 7, 2020
DOI https://doi.org/ 10.1055/s-0040-1721902 ISSN 2582-4287.
C 2020. Nitte (Deemed to be University).

This is an open access article published by Thieme under the terms of the Creative Commons Attribution-NonDerivative-NonCommercial-License, permitting copying and reproduction so long as the original work is given appropriate credit. Contents may not be used for commercial purposes, or adapted, remixed, transformed or built upon. (https://creativecommons.org/licenses/by-nc-nd/4.0/)

Thieme Medical and Scientific Publishers Pvt. Ltd. A-12, 2nd Floor, Sector 2, Noida-201301 UP, India 


\section{Introduction}

Diabetes mellitus (DM), long regarded as a disease of minor importance for world health, is now one of the major threats to human health in the 21st century. An estimated 366 million people today have DM, accounting for $8.3 \%$ of the world's adult population, but the prevalence is expected to increase to 552 million by 2030 , corresponding to $9.9 \%$ of the adult population. ${ }^{1}$ India with a population of 61.3 million DM ranks second after China. ${ }^{2}$

The increased prevalence of DM seems to be fueled by rapid urbanization, nutritional transition, and increasingly sedentary lifestyles. ${ }^{3}$ The prevalence ranges from $2.4 \%$ (rural) to $11.6 \%$ (urban) in south India. ${ }^{4,5}$ As the disease is chronic and progressive in nature, it implicates a significant financial burden on the patient. ${ }^{6}$ As per World Health Organization estimates, DM drain an important percent of the health budget by price toward diabetic care. ${ }^{7}$ All the expenses incurred for the direct and indirect costs were met out-of-pocket (OOP) by the patients. ${ }^{8}$ People with financial constraints may experience additional financial stress due to their health, which can lead to poverty. ${ }^{9}$ Many health practitioners worldwide only concentrate on treatment and are unaware of diabetics social and economic impacts. This lack of awareness is the biggest obstacle to successful prevention approaches, which could help avoid the inexorable rise in type II DM. ${ }^{10}$ Therefore, assessing the current economic burden of disease on the health care system helps decision-makers understand the magnitude of the problem, prioritize research efforts, and plan resource allocation to manage the condition properly. The objectives of this study were (1) to estimate DM treatment-related OOP expenditure (OOPE) among type 2 DM patients with complications from a tertiary care hospital and (2) to estimate the economic burden on the household income of these patients due to DM treatment-related OOPE

\section{Materials and Methods}

A hospital-based cross-sectional study was conducted among known type 2 diabetic individuals with complications aged 18 to 80 years admitted to the Department of General Medicine, Sri Manakula Vinayagar Medical College and Hospital, for a period of 6 months (April to September 2019) after getting informed consent; approval from the Institutional Research and Ethics Committees was taken prior to the study. Patients with both type 2 DM and systemic hypertension, as well as cases of gestational DM, type $1 \mathrm{DM}$, and other forms of DM were excluded from the study.

\section{Target Population and Sampling Technique}

Purposive sampling technique was used as the study population constituted inpatients of the Department of General Medicine with DM and its complications from a total inpatient population (target population) of around 2,000 (based on previous years statistics) available for the study period of 6 months.

\section{Sample Size Estimation}

Based on the prevalence of 7\% catastrophic OOPE on DM medications in India found by Gwatidzo and Williams in 2017 and considering the study population available during the study period as 2,000 at $95 \%$ confidence interval, the sample size was calculated to be 96 using the Open Epi software version 3 , which was rounded off to 100 finally. ${ }^{11}$

\section{Operational Definitions}

- Family: a family is a group of two or more persons related by birth, marriage, or adoption who live together. ${ }^{12}$

- OOPE: it is any direct outlay by households, including gratuities and in-kind payments to health practitioners and suppliers of pharmaceuticals, therapeutic appliances, and other goods and services whose primary intent is to contribute to the restoration or enhancement of health status of individuals or population groups. It is a part of private health expenditure. ${ }^{13}$

- Catastrophic OOPE: It is the OOPE exceeding $40 \%$ of household income net devoid of subsistence needs. ${ }^{13}$

- "Economic burden of DM care on household" or ratio of OOPE for disease-specific health care to effective household income: indicator is calculated as OOPE for health care for specific disease divided by "Total effective household income" (total income-subsistence needs of the family for a month) multiplied by $100 .{ }^{13}$

\section{Data Collection Procedure}

Data collection was performed by administering a structured pretested questionnaire. The questionnaire contained details such as sociodemographic details, educational status, occupational details, DM-related history, complications of DM, family history of DM, treatment details, and medical and nonmedical costs related to treatment. The direct medical cost per patient included expenditure for medical consultations, laboratory charges, medicine, and money spent on other investigation, and indirect cost included the expenses for accompanying attendant and transportation, health education/training classes, and diet control package.

\section{Statistical Analysis}

The information obtained from the questionnaire was entered using Microsoft Excel and analyzed using SPSS software version 24 (IBM Corp., Armonk, New York, United States). Categorical variables were presented as proportions. Mean with standard deviation as well as median with interquartile range were used respectively for normally and non-normally distributed continuous variables. Bivariate analysis was used to identify associated factors, and multivariate logistic regression was performed to identify determinants. The comparisons and associations with a $p$-value $<0.05$ were considered to be statistically significant.

\section{Results}

Sociodemographic Characteristics of the Respondents A total of 100 patients were enrolled in the study of which $57 \%$ were male and $43 \%$ were female. The mean age 
of the population was $56 \pm 10.03$ years, ranging from 32 to 78 years. As for educational status, $23 \%$ were illiterate and $39 \%$ had only primary education. Regarding occupation status, it was found that only $47 \%$ of the patients were currently employed. Of the study population, $71 \%$ resided in rural areas. Majority of the patients were suffering from the disease for a long duration (6-9 years: 44\%; >10 years: $26 \%)$. Only $43 \%$ of the participants adhere to dietary advice and only $19 \%$ had been pursuing good physical activity. None of the participants had attended health care classes. Nearly half of the participants do regular monthly diabetic check-up (-Table 1).

\section{Diabetic Complications}

Among 100 patients, 32\% had neurological complications, 31\% had cardiovascular and retinal complications, and 26\% had other complications such as the diabetic foot. Around $46 \%$ of the study participants were hospitalized in the last 6 months due to diabetic-related complications (-Fig. 1).

\section{Types of Drugs Prescribed}

On the evaluation of the management of DM, 20\% of patients received insulin alone, $47 \%$ received oral hypoglycemic agents (OHAs) alone, and 33\% received both insulin and OHA's (- Table 1).

\section{Impact of Diabetes on Socioeconomic Aspects of Life} Of the four domains-psychological, physical, social, and environmental health-DM mostly affected physical health. The study showed that more than half of the study population (58\%) experienced fatigue, and a significant portion (31\%) had pins and needle sensation leading to decreased productivity at work (33\%). In the environmental domain, 41\% patients experienced financial burden because of increased health care costs, $32 \%$ revealed that social support is not at an optimum level, $20 \%$ of the study population were bedridden, and $14 \%$ experienced reduced participation in leisure activities due to diabetic complications (-Fig. 2).

\section{Cost of Treatment}

A large proportion (66\%) of patients availed treatment from the private sector, and only $12 \%$ had health insurance. Various components of cost for care for DM with complications among patients who were admitted in the medicine wards are given in - Table $\mathbf{2}$ with median and IQR.

\section{Direct Cost}

The mean monthly income of the family (in Indian Rupees [INR]) was $10,375.00 \pm 9,201.55$. Among those from government facilities, there was little or no expenditure for medicine, clinician fees, and investigation, and whereas those from private facilities incurred high costs for the same. Among them, the median cost of physician consultation for DM and its complications was INR 100 per visit, and the median cost of medicines and investigations were INR 615 per month and INR 200 per visit, respectively.
Table 1 Sociodemographic and clinical characteristics of study population $(n=100)$

\begin{tabular}{|c|c|}
\hline Characteristics & $n(\%)$ \\
\hline \multicolumn{2}{|l|}{ Age (years) } \\
\hline $20-40$ & $7(7 \%)$ \\
\hline $41-60$ & $57(57 \%)$ \\
\hline $61-80$ & $36(36 \%)$ \\
\hline \multicolumn{2}{|l|}{ Gender } \\
\hline Male & $57(57.0 \%)$ \\
\hline Female & $43(43.0 \%)$ \\
\hline \multicolumn{2}{|l|}{ Marital status } \\
\hline Married & $86(86.0 \%)$ \\
\hline Widow and widower & $10(10.0 \%)$ \\
\hline Living separate & $4(4.0 \%)$ \\
\hline \multicolumn{2}{|l|}{ Education } \\
\hline Illiterate & $23(23.0 \%)$ \\
\hline Primary & $39(39.0 \%)$ \\
\hline Middle & $27(27.0 \%)$ \\
\hline High school and intermediate & $8(8.0 \%)$ \\
\hline Graduate and postgraduate & $3(3.0 \%)$ \\
\hline \multicolumn{2}{|l|}{ Occupation } \\
\hline Unemployed & $23(23.0 \%)$ \\
\hline Unskilled & $33(33.0 \%)$ \\
\hline Semiskilled and skilled & $13(13.0 \%)$ \\
\hline Retired & $3(3.0 \%)$ \\
\hline Homemaker & $27(27.0 \%)$ \\
\hline \multicolumn{2}{|l|}{ Income } \\
\hline Less than or equal to 5,000 & $38(38 \%)$ \\
\hline 5,001 to 10,000 & $33(33 \%)$ \\
\hline More than 10,001 & $29(29 \%)$ \\
\hline \multicolumn{2}{|l|}{ Residential status } \\
\hline Urban & $29(29.0 \%)$ \\
\hline Rural & $71(71.0 \%)$ \\
\hline \multicolumn{2}{|l|}{ Diabetes background } \\
\hline \multicolumn{2}{|l|}{ Duration (years) } \\
\hline$<5$ & $30(30 \%)$ \\
\hline $6-10$ & $44(44 \%)$ \\
\hline$>10$ & $26(26 \%)$ \\
\hline \multicolumn{2}{|l|}{ Frequency of sugar check } \\
\hline Irregular & $1(1.0 \%)$ \\
\hline Monthly & $49(49.0 \%)$ \\
\hline Once in $2 \mathrm{mo}$ & $37(37.0 \%)$ \\
\hline Once in $3 \mathrm{mo}$ & $13(13.0 \%)$ \\
\hline \multicolumn{2}{|l|}{ Medication } \\
\hline $\mathrm{OHA}$ & $47(47.0 \%)$ \\
\hline Insulin & $20(20.0 \%)$ \\
\hline $\mathrm{OHA}+$ insulin & $33(33.0 \%)$ \\
\hline
\end{tabular}

Abbreviation: OHA, oral hypoglycemic agent.

Note: As the sample size is 100 , the percentage and frequency are the same.

\section{Indirect Cost of Diabetes Mellitus Management}

Significant expenditure was seen only for miscellaneous reasons and travel for government facility patients (INR 23 and 50 , respectively), whereas for private facilities, mean cost 


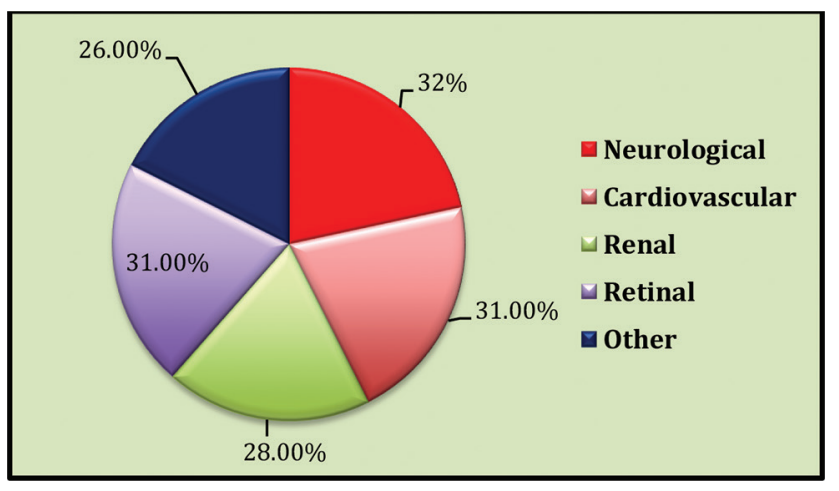

Fig. 1 Distribution of diabetic complications.

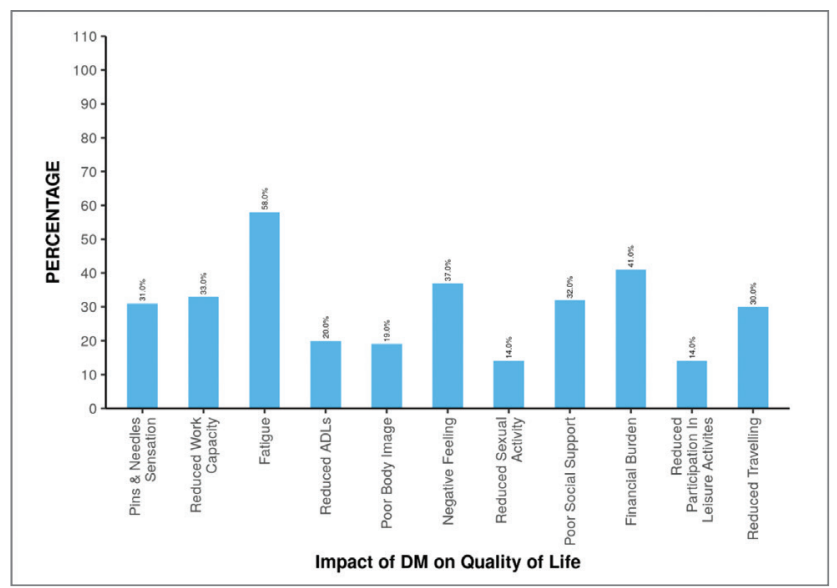

Fig. 2 Impact of diabetes on socioeconomic aspects of life. DM, diabetes mellitus. of transportation was INR 157 per visit and miscellaneous expenditure cost was INR 231 per month.

\section{Total Cost of Treatment}

This included all the costs of medical treatment, investigation, consultation fee, intervention cost, and transportation. The median total expenditure in the management of DM for 1 month for government and private facilities was INR 50 and 1,150, respectively (-Table 2 ). Among the total cost, the highest share was accrued toward medicines followed by diagnostics, miscellaneous, and transportation (-Table 2).

Almost 50\% of families were incurring a monthly OOPE, which was less than $10 \%$ of their "effective monthly household income." There were $36 \%$ families spending $21 \%$ or more of their "effective monthly household income" and $22 \%$ families were facing catastrophic OOPE (40\% or more share of their effective household income) for DM carec ( - Table 3 ).

Table 3 Distribution of households based on various thresholds of OOPE based on WHO criteria

\begin{tabular}{|l|l|l|l|l|}
\hline $\begin{array}{l}\text { Thresholds of ratio } \\
\text { of OOPE for DM } \\
\text { treatment to effective } \\
\text { household income }\end{array}$ & $\mathbf{1 0 \%}$ & $\mathbf{2 1 1 \%}$ & $\mathbf{2 2 1 \%}$ & $\mathbf{2 4 0 \%}$ \\
\hline $\begin{array}{l}\text { Share of households } \\
\text { experiencing in } \\
\text { percentage }\end{array}$ & 50 & 50 & 36 & 22 \\
\hline
\end{tabular}

Abbreviations: DM, diabetes mellitus; OOPE, out-of-pocket expenditure; WHO, World Health Organization.

Table 2 OOPE of patients receiving diabetic care

\begin{tabular}{|c|c|c|c|c|}
\hline Type of expenditure & Type of facility & Mean (SD) & Median (IQR) & $p$-Value \\
\hline \multirow[t]{2}{*}{ Medicines } & Government & $0(0)$ & $0(0)$ & \multirow[t]{2}{*}{$<0.001^{\mathrm{a}}$} \\
\hline & Private & $803.82(885.39)$ & $651(691)$ & \\
\hline \multirow[t]{2}{*}{ Clinician fees } & Government & $0(0)$ & $0(0)$ & \multirow[t]{2}{*}{$<0.001^{\mathrm{a}}$} \\
\hline & Private & $83.71(94.92)$ & $100(100)$ & \\
\hline \multirow[t]{2}{*}{ Investigation } & Government & $0(0)$ & $0(0)$ & \multirow[t]{2}{*}{$<0.001^{\mathrm{a}}$} \\
\hline & Private & $264.24(269.07)$ & $200(413)$ & \\
\hline \multirow[t]{2}{*}{ Spectacles } & Government & $11.76(68.60)$ & $0(0)$ & \multirow[t]{2}{*}{$<0.001^{\mathrm{a}}$} \\
\hline & Private & $234.85(309.71)$ & $0(400)$ & \\
\hline \multirow[t]{2}{*}{ Travel } & Government & $50.88(38.26)$ & $50(62)$ & \multirow[t]{2}{*}{$0.016^{\mathrm{a}}$} \\
\hline & Private & $157.15(251.90)$ & $90(85)$ & \\
\hline \multirow[t]{2}{*}{ Miscellaneous } & Government & $23.24(36.91)$ & $0(50)$ & \multirow[t]{2}{*}{0.283} \\
\hline & Private & $231.21(1,119.74)$ & $50(100)$ & \\
\hline \multirow[t]{2}{*}{ Total expenditure } & Government & $74.12(65.10)$ & $50(89)$ & \multirow[t]{2}{*}{$<0.001^{\mathrm{a}}$} \\
\hline & Private & $1,540.14(2,097.11)$ & $1,150(1,066)$ & \\
\hline
\end{tabular}

Abbreviations: IQR, interquartile range; OOPE, out-of-pocket expenditure; SD, standard deviation.

aStatistically significant $p$-values. 
Bivariate analysis of various independent variables against the outcome variable of "economic burden of DM care on household" ( - Table 4) showed that associations of socioeconomic status (SES), history of at least one hospitalization in the past 6 months, type of medications used, and occupation were found to be statistically significant. These associations were selected to be analyzed by multivariate analysis where the confounding factors can be adjusted and true determinants could be found.

The multivariate analysis of associated factors with "economic burden of DM care on household" (-Table 5) revealed that households of unemployed or not working

Table 4 Bivariate analysis of various factors with economic burden of DM treatment on households

\begin{tabular}{|c|c|c|c|c|}
\hline Variables & $\begin{array}{l}\text { Noncatastrophic } \\
\text { expenditure }(<40 \%)\end{array}$ & $\begin{array}{l}\text { Catastrophic } \\
\text { expenditure (>40\%) }\end{array}$ & $\begin{array}{l}\text { Chi-square } \\
\text { value }\end{array}$ & $p$-Value \\
\hline \multicolumn{5}{|l|}{ Age category } \\
\hline$<60$ years & 48 & 10 & \multirow[t]{2}{*}{1.822} & \multirow[t]{2}{*}{0.233} \\
\hline$>60$ years & 30 & 12 & & \\
\hline \multicolumn{5}{|l|}{ Occupation } \\
\hline $\begin{array}{l}\text { Unskilled, semiskilled and skilled, } \\
\text { semiprofessional }\end{array}$ & 41 & 6 & 4.406 & $0.030^{\mathrm{a}}$ \\
\hline Home maker, retired, unemployed & 37 & 16 & & \\
\hline \multicolumn{5}{|l|}{ Insurance } \\
\hline Yes & 11 & 1 & 1.484 & 0.293 \\
\hline No & 67 & 21 & & \\
\hline \multicolumn{5}{|l|}{ Residence } \\
\hline Rural & 57 & 14 & 0.743 & 0.430 \\
\hline Urban & 21 & 8 & & \\
\hline \multicolumn{5}{|l|}{ Distance from hospital } \\
\hline$<40 \mathrm{~km}$ & 70 & 18 & 1.021 & 0.456 \\
\hline$>40 \mathrm{~km}$ & 8 & 4 & & \\
\hline \multicolumn{5}{|l|}{ Duration of DM } \\
\hline$<10$ years & 59 & 15 & 0.496 & 0.583 \\
\hline$>10$ years & 19 & 7 & & \\
\hline \multicolumn{5}{|l|}{ Medications used } \\
\hline $\mathrm{OHA}$ & 41 & 6 & 4.406 & $0.030^{\mathrm{a}}$ \\
\hline Insulin alone or with $\mathrm{OHA}$ & 37 & 16 & & \\
\hline \multicolumn{5}{|l|}{ Regularity of blood sugar check-up } \\
\hline Irregular, once in 2 and 3 mo & 40 & 11 & 0.011 & 1.000 \\
\hline Monthly once & 38 & 11 & & \\
\hline \multicolumn{5}{|l|}{ Complications of DM } \\
\hline Only one complication & 50 & 12 & 0.665 & 0.461 \\
\hline More than one complications & 28 & 10 & & \\
\hline \multicolumn{5}{|l|}{ Hospitalization for last 6 mo } \\
\hline No & 48 & 6 & 8.111 & $0.007^{\mathrm{a}}$ \\
\hline Yes & 30 & 16 & & \\
\hline \multicolumn{5}{|l|}{ Socioeconomic status } \\
\hline $\begin{array}{l}\text { Middle class, upper middle class, } \\
\text { upper class }\end{array}$ & 52 & 4 & 16.372 & $<0.001^{\mathrm{a}}$ \\
\hline Lower class, lower middle class & 26 & 18 & & \\
\hline
\end{tabular}

Abbreviations: DM, diabetes mellitus; OHA, oral hypoglycemic agent.

a Statistically significant $p$-values. 
Table 5 Multivariate analysis of associated factors with economic burden of DM treatment on households

\begin{tabular}{|c|c|c|c|c|}
\hline Variables & $\begin{array}{l}\text { Noncatastrophic } \\
\text { expenditure }(<40 \%)\end{array}$ & $\begin{array}{l}\text { Catastrophic } \\
\text { expenditure (>40\%) }\end{array}$ & Odds ratio $(95 \% \mathrm{CI})$ & $p$-Value \\
\hline \multicolumn{5}{|l|}{ Socioeconomic status } \\
\hline $\begin{array}{l}\text { Upper and middle } \\
\text { classes }\end{array}$ & 52 & 4 & 1 & \multirow[t]{2}{*}{$0.001^{\mathrm{a}}$} \\
\hline Lower classes & 26 & 18 & $8.07(2.36-27.66)$ & \\
\hline \multicolumn{5}{|c|}{ Hospitalization for last 6 mo } \\
\hline No & 48 & 6 & 1 & \multirow[t]{2}{*}{0.116} \\
\hline Yes & 30 & 16 & $2.62(0.79-8.69)$ & \\
\hline \multicolumn{5}{|l|}{ Medications used } \\
\hline $\mathrm{OHA}$ & 41 & 6 & 1 & \multirow[t]{2}{*}{0.340} \\
\hline $\begin{array}{l}\text { Insulin alone or } \\
\text { with } \mathrm{OHA}\end{array}$ & 37 & 16 & $1.83(0.53-6.32)$ & \\
\hline \multicolumn{5}{|l|}{ Occupation } \\
\hline Employed & 41 & 6 & 1 & \multirow[t]{2}{*}{0.157} \\
\hline $\begin{array}{l}\text { Unemployed or not } \\
\text { working }\end{array}$ & 37 & 16 & $2.34(0.72-7.63)$ & \\
\hline
\end{tabular}

Abbreviations: $\mathrm{Cl}$, confidence interval; DM, diabetes mellitus; OHA, oral hypoglycemic agent.

aStatistically significant $p$-value.

patients were 2.34 times more prone to facing catastrophic OOPE for DM treatment than those of employed patients of DM. Similarly, those using insulin alone or along with OHA were 1.83 times and those who were hospitalized at least once in the last 6 months were 2.62 times more prone to catastrophic OOPE than those using OHA alone and not hospitalized in past 6 months, respectively. But these associations were not statistically significant. Only statistically significant association for catastrophic OOPE was SES. Those belonging to lower SES were 8.07 times more prone to experiencing catastrophic OOPE for DM treatment than those of upper and middle classes.

\section{Discussion}

The results of the current research are consistent with those of other studies performed to determine the economic burden of DM care on the households of patients. The mean age of the participants in this study was 51 years, which is similar to research by Mohan et al to assess the trends in the prevalence of DM and glucose tolerance in urban south India, where $50 \%$ of the patients with DM were between 40 and 59 years of age, which indicates a large burden of DM in the middle-aged population. ${ }^{14}$ Fernandes and Fernandes' study on the economic burden of DM and its socioeconomic impact on household expenditure in the urban slum area reported an average consultation cost of 77.9 INR and mean investigation and medicine cost of 85 INR and 287 INR per month, respectively, totaling an overall direct cost of 687 per month. The mean cost of transportation and miscellaneous expenditure was 30 and 9.58 INR, totaling to indirect cost of 348.75 INR per month, where the direct cost of care is approximate twice the indirect cost of care, whereas our study shows that direct cost $(1,384$ INR) is triple the indirect cost of treatment (388 INR). ${ }^{15}$ The average total expenditure in the current study is 1,540 INR per month, whereas in a study by Ramachandran et al, it is 833.33 per month. ${ }^{10}$ In a study conducted in North India by Grover et al, it was reported that the overall cost of DM care was around INR 14,517.42 per person annually, which is somewhat comparable to what was found in this study. ${ }^{16}$ A study by Fernandes and Fernandes shows that $5.8 \%$ of study participants bear catastrophic expenditure, whereas our study shows that $22 \%$ of families were facing catastrophic OOPE, which meant that $22 \%$ spent more than INR 40 on DM if their net monthly effective income was INR $100 .{ }^{15}$ In a study by Javalkar on the economic burden of health expenditure on DM, the use of health insurance schemes was $2 \%$, whereas our study shows this as $12 \% .{ }^{17}$ In our study, drug or insulin expenditure accounted for the highest portion of expenditure, which was similar to the study conducted by Kapoor et al that suggested the need for supply of insulin in primary care level. ${ }^{18}$ Javalkar had found that the expenditure on DM treatment increases with several complications, which was not seen in our study. ${ }^{17}$ A study by Chandra et al showed that patients in lower socioeconomic class spend a larger proportion of their income in managing DM, a finding similar to our study. ${ }^{6}$ Our study shows that patients spend an average of 15\% of their family income on the disease. This is in consonance with findings reported by Kumar et al, where the direct cost of DM care was found to be 1 to $3 \%$ of the gross family income. ${ }^{19}$ Our study had found that SES, history of at least one hospitalization in the past 6 months, type of medications used, and occupation were associated with "economic burden of DM care on household." Even though the multivariate analysis where the possible effect of confounders was adjusted for, we could find only SES as the lone determinant of catastrophic OOPE on DM care due to the fact that the aforementioned factors were 
associated with "economic burden of DM care on household" cannot be ignored. Another very important finding of our study was the costs incurred for accompanying person, food, transportation, and miscellaneous needs, which were contributing significantly toward the total expenditure on DM care. This is very important because these findings point toward the need for policymakers to consider the nonmedical aspects of DM care, which contributes toward the total burden. There is a need for socioeconomic management of the disease wherein provisions to lessen these burden should be taken by policymakers. Comprehensive coverage of government-funded health insurance for poorer sections of the population, which can be incorporated through public-private partnership basis in private hospitals, too seems to be a solution for addressing this issue

The limitations of this study are as follows. This is a questionnaire-based study, and the expenses were recorded as reported by the patients and therefore could be subjective to recall bias, which would have had the effect of underestimating or overestimating OOPE. Indirect costs due to decreased productivity could not be measured in this study. This study covers only type 2 diabetic patients. The sample size was limited as it was a hospital-based study.

\section{Conclusion}

Catastrophic OOPE due to the treatment of type 2 DM may have disastrous consequences on the economic well-being of the patient's family. Keeping in mind the epidemic potential of DM, this heavy economic burden highlights the urgent need for the health care agencies and policy bodies to plan and prioritize local health policies and DM management schemes accordingly.

The research recommendations are as follows: (1) accessibility and availability of quality health care should be improved to support low-income communities, (2) high costs and suboptimal access to cost-effective drugs should be tackled by market-shaping strategies, (3) undertaking health educational initiatives, initially encouraging patients with DM to maintain a healthy diet and exercise regime followed by early diagnosis and treatment, (4) Incorporating tertiary care level DM care at primary- and secondary-level health centers at least on an ambulatory basis, and (5) issuing subsidized cost travel passes for patients requiring frequent visits to the hospital.

\section{Conflict of Interest}

None declared.

\section{References}

1 Zimmet P. Globalization, coca-colonization and the chronic disease epidemic: can the Doomsday scenario be averted? J Intern Med 2001;249(S741) :17-26
2 Gupta M, Singh R, Lehl S. Diabetes in India: a long way to go. International Journal of Scientific Reports 2015;1(1):1-2

3 Hu FB. Globalization of diabetes: the role of diet, lifestyle, and genes. Diabetes Care 2011;34(6):1249-1257

4 Ramachandran A, Jali MV, Mohan V, Snehalatha C, Viswanathan M. High prevalence of diabetes in an urban population in south India. BMJ 1988;297(6648):587-590

5 Ramachandran A, Snehalatha C, Satyavani K, Sivasankari S, Vijay V. Metabolic syndrome in urban Asian Indian adults-a population study using modified ATP III criteria. Diabetes Res Clin Pract 2003;60(3):199-204

6 Chandra P, Gogate B, Gogate P, Thite N, Mutha A, Walimbe A. Economic burden of diabetes in urban Indians. Open Ophthalmol J 2014;8:91-94

7 Mohan V, Madan Z, Jha R, Deepa R, Pradeepa R. Diabetes-social and economic perspectives in the new millenium. Int J Diabetes Dev Ctries 2004;24(2):29-35

8 Ramaiya KL, Kodali VR, Alberti KG. Epidemiology of diabetes in Asians of the Indian subcontinent. Diabetes Metab Rev 1990;6(3):125-146

9 Goryakin Y, Suhrcke M. The prevalence and determinants of catastrophic health expenditures attributable to non-communicable diseases in low- and middle-income countries: a methodological commentary. Int J Equity Health 2014;13(1):107

10 Ramachandran A, Ramachandran S, Snehalatha C, et al. Increasing expenditure on health care incurred by diabetic subjects in a developing country: a study from India. Diabetes Care 2007;30(2):252-256

11 Gwatidzo SD, Williams JS. Diabetes mellitus medication use and catastrophic healthcare expenditure among adults aged 50+ years in China and India: results from the WHO study on global AGEing and adult health (SAGE) BMC Geriatr 2017;17(1):14

12 US Health Resources \& Services Administration. Definition of Family. 2020. Available at: https://www.hrsa.gov/gethealth-care/affordable/hill-burton/family.html\#: :text=Family\%3A\%20A\%20family\%20is\%20a,as\%20members\%20of\%20 one\%20family. Accessed December 21, 2020

13 World Bank. Out-of-pocket expenditure (\% of current health expenditure). Available at: https://data.worldbank.org/indicator/SH.XPD.OOPC.CH.ZS. Accessed March 16, 2017

14 Mohan V, Deepa M, Deepa R, et al. Secular trends in the prevalence of diabetes and impaired glucose tolerance in urban South India-the Chennai Urban Rural Epidemiology Study (CURES-17) Diabetologia 2006;49(6):1175-1178

15 Fernandes SD, Fernandes SD. Economic burden of diabetes mellitus and its socio-economic impact on household expenditure in an urban slum area. Int J Res Med Sci. 2017;5(5):1808-3

16 Grover S, Avasthi A, Bhansali A, Chakrabarti S, Kulhara P. Cost of ambulatory care of diabetes mellitus: a study from north India. Postgrad Med J 2005;81(956):391-395

17 Javalkar SR. The economic burden of health expenditure on diabetes mellitus among urban poor: a cross sectional study. Int. J Comm Med Pub Health 2019;6(3):1162

18 Kapur A, Bjork S, Nair J, Kelkar S, Ramachandran A. Socioeconomic determinants of the cost of diabetes in India. Diabetes Voice. 2004;49:18-23

19 Kumar A, Nagpal J, Bhartia A. Direct cost of ambulatory care of type 2 diabetes in the middle and high income group populace of Delhi: the DEDICOM survey. J Assoc Physicians India 2008;56:667-674 